\title{
Fabrication and characterization of hydrophobic PVDF hollow fiber membranes for desalination through direct contact membrane distillation
}

\author{
Deyin Hou, Jun Wang*, Dan Qu, Zhaokun Luan, Xiaojing Ren \\ State Key Laboratory of Environmental Aquatic Chemistry, Research Center for Eco-Environmental Sciences, Chinese Academy of Sciences, \\ P.O. Box 2871, Beijing 100085, PR China
}

\section{A R T I C L E I N F O}

\section{Article history:}

Received 23 February 2009

Received in revised form 4 June 2009

Accepted 29 June 2009

\section{Keywords:}

Membrane distillation

Desalination

Polyvinylidene fluoride

Hydrophobic

\begin{abstract}
A B S T R A C T
The mixture of inorganic salt LiCl and soluble polymer polyethylene glycol (PEG) 1500 as non-solvent additive was introduced to fabricate hydrophobic hollow fiber membrane of polyvinylidene fluoride (PVDF) by phase inversion process, using $\mathrm{N}, \mathrm{N}$-dimethylacetamide (DMAc) as solvent and tap water as the coagulation medium. Compared with other three membranes from PVDF/DMAc, PVDF/DMAc/LiCl and PVDF/DMAc/PEG 1500 dope solution, it can be observed obviously by scanning electron microscope (SEM) that the membrane spun from PVDF/DMAc/LiCl/PEG 1500 dope had longer finger-like cavities, ultra-thin skins, narrow pore size distribution and porous network sponge-like structure owing to the synergistic effect of $\mathrm{LiCl}$ and PEG 1500. Besides, the membrane also exhibited high porosity and good hydrophobicity. During the desalination process of $3.5 \mathrm{wt} \%$ sodium chloride solution through direct contact membrane distillation (DCMD), the permeate flux achieved $40.5 \mathrm{~kg} / \mathrm{m}^{2} \mathrm{~h}$ and the rejection of $\mathrm{NaCl}$ maintained $99.99 \%$ with the feed solution at $81.8^{\circ} \mathrm{C}$ and the cold distillate water at $20.0^{\circ} \mathrm{C}$, this performance is comparable or even higher than most of the previous reports. Furthermore, a $200 \mathrm{~h}$ continuously desalination experiment showed that the membrane had stable permeate flux and solute rejection, indicating that the as-spun PVDF hollow fiber membrane may be of great potential to be utilized in the DCMD process.
\end{abstract}

(C) 2009 Elsevier B.V. All rights reserved.

\section{Introduction}

Membrane distillation (MD) is a new membrane separation process and usually applied in which water is the major component present in the feed solution to be treated [1]. The permeate flux of $\mathrm{MD}$ is driven by a vapor pressure difference across the membrane resulting from the temperature difference and solution composition gradients in the boundary layers adjacent to the membrane [2]. The MD process may be used as a substitute for conventional separation processes such as multistage vacuum evaporation, reverse osmosis, and distillation [3]. Compared to those processes, the advantages of MD are as follows: (1) lower operating temperature and vapor space required than conventional distillation, (2) lower operating pressure than $\mathrm{RO}$, (3) 100\% (theoretical) rejection of non-volatile solute, (4) unlimited by high osmotic pressure, and (5) lower energy consumption than multistage vacuum evaporation $[4,5]$.

MD processes have several different configurations which can be named as direct contact membrane distillation (DCMD), air gap membrane distillation (AGMD), sweeping gas membrane distil-

\footnotetext{
* Corresponding author. Tel.: +86 10 62849150; fax: +86 1062849150 .

E-mail address: junwang@rcees.ac.cn (J. Wang).
}

lation (SGMD) and vacuum membrane distillation (VMD). More details and extended explanations of MD process can be found in several articles [6-10]. In these existed modes, most MD experiments are carried out by using DCMD, which is the simplest system in design because condensation is carried out inside the membrane module and appears as the best for application.

For an MD process, the porous membrane only acts as a barrier, but it plays a crucial role. The membrane prevents the penetration of the aqueous solution into its dry pores by its hydrophobic nature until the liquid entry pressure of water (i.e., LEPw) is exceeded. Besides, the membrane properties, such as pore size, pore size distribution and porosity will also influence the MD performance [11-14]. Therefore, good hydrophobicity, appropriate pore size and narrow pore size distribution of microporous membranes are necessary to ensure the high permeate flux and rejection in MD process.

Nowadays, polytetrafluoroethylene (PTFE), polypropylene (PP) and polyvinylidene fluoride (PVDF) are most popular and available hydrophobic membrane materials. Among these three polymers, only PVDF can be used for the preparation of asymmetric membranes using the Loeb-Sourirajan phase inversion method [15]. In addition, the PVDF shows good chemical resistance, particularly the oxidant resistance. Hence, PVDF has been a subject of active research in polymer science and has received increasing attention for various membrane separations [16]. Although an extensive 
series of studies have been carried out to fabricate PVDF membranes in order to improve their properties, most of them are focused on preparation of flat sheet membranes [17-20] and hydrophilic hollow fiber membranes [21-25], less research has been conducted on the fabrication and characterization of hydrophobic porous PVDF hollow fiber membranes mainly for the MD process [1].

One of the efficient and simple methods is the introduction of suitable additives into the polymer solution to improve hollow fiber formation and its properties. It has been shown that the addition of $\mathrm{LiCl}$ can change the coagulation path and rate, increase membranes porosity $[18,26,27]$ and water soluble polymer polyethylene glycol (PEG) can be used for reducing the skin layer thickness [28-30]. However, as far as we know, there is no report on the preparation of hydrophobic PVDF hollow fiber membranes with the mixture of $\mathrm{LiCl}$ and PEG as non-solvent additive.

The present investigation was carried out to fabricate asymmetric porous PVDF hollow fiber membranes with the mixture of $\mathrm{LiCl}$ and PEG 1500 as non-solvent additive, which was especially fit for the MD process, with high permeate flux and good hydrophobicity. The membranes properties also were tested and characterized via DCMD in this work.

\section{Materials and methods}

\subsection{Materials}

PVDF (FR-904) was obtained from Shanghai 3F new materials Co., Ltd. (China). The molecular weight (Mw) of PVDF is about $1.02 \times 10^{6} \mathrm{~g} / \mathrm{mol}$, measured by GPC (waters, 515). N,Ndimethylacetamide (DMAc, >99\%) was employed as the solvent, purchased from Shanghai Jingwei Chemical Co., Ltd. (China). A mixture of $\mathrm{LiCl}$ and PEG 1500 used as non-solvent additive in the polymer solution, $\mathrm{LiCl}(95.0 \%)$ and PEG 1500 ( Mw =1500, >99.5\%) were supplied by Tianjin Guangfu Research Institute of Fine Chemical Engineering (China). Ethanol (GR grade, 99.9\%) and $\mathrm{NaCl}(99.5 \%)$ were from Beijing Chemical works (China). Ultrapure water and tap water were used as the internal and external coagulant respectively.

\subsection{Dope preparation}

The PVDF powder was dried at $100^{\circ} \mathrm{C}$ under vacuum for $24 \mathrm{~h}$ to remove its moisture content before it was used for dope preparation. A desired amount of dried PVDF powder was weighed and poured into a DMAc solvent and non-solvent additive mixture, then the polymer dope mixture was subjected to continuous stirring for about $48 \mathrm{~h}$ at $50^{\circ} \mathrm{C}$ in order to ensure it homogeneous. In this work, a polymer solution made of 12.0/80/5.0/3.0 (in wt\%) PVDF/DMAc/LiCl/PEG 1500 was chosen to fabricate hydrophobic porous PVDF membranes. The mixture of $\mathrm{LiCl}$ and PEG 1500 as nonsolvent additive is beneficial not only to obtain a membrane with porous structure, but also to produce a super-thin skin layer.

Other dope solutions such as PVDF/DMAc (12/88, wt\%), PVDF/DMAc/LiCl (12/83/5, wt\%) and PVDF/DMAc/PEG 1500 $(12 / 83 / 5$, wt\%) were also prepared as comparisons.

\subsection{Spinning of PVDF hollow fiber membranes}

The method of preparation involved is the same as that of the "phase inversion" method employed in earlier works as reported by other researchers [31], and the process of hollow fiber spinning is schematically shown in Fig. 1 . The formulated dope and bore fluid were filtered by a metal filter $(15 \mu \mathrm{m})$ and degassed before spinning to remove the particles and gas bubbles that may exist in the dope. The homogeneous polymer solution was fed into the spinneret by a gear pump (WB-85, Zhejiang Dongfang Driving

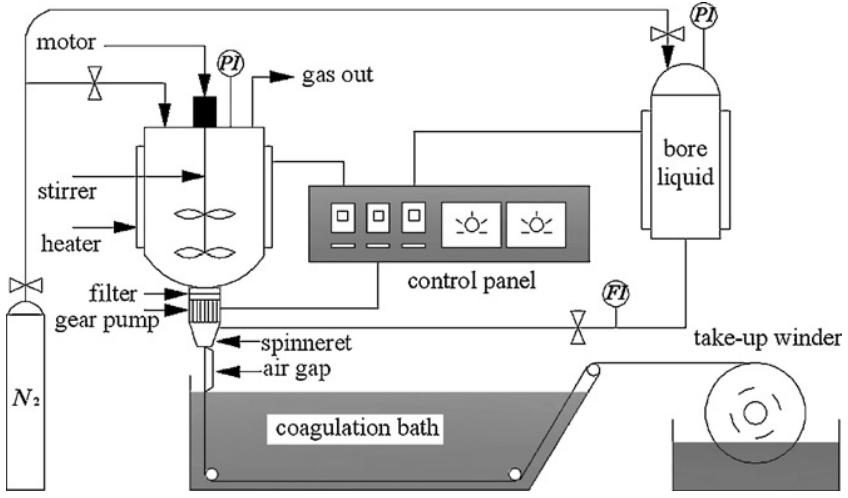

Fig. 1. Schematic diagram of a hollow fiber spinning line.

Machine, China) with a speed controller under the nitrogen pressure of $0.2 \mathrm{MPa}$, and ultrapure water was used as bore liquid fed into the spinneret through a flow meter (LZB-3WB, Yuyao Zhenxing Flowmeters, China) under the same nitrogen pressure to make a lumen of the hollow fiber. The spinneret had outer and inner tubes, the diameters were 1.4 and $0.7 \mathrm{~mm}$, respectively. Once the spinning dope and the bore liquid met at the tip of the spinneret, they entered the coagulation bath straight away. The nascent fiber was wound on a take-up winder after entering into a water bath kept at $20^{\circ} \mathrm{C}$ to induce the phase separation and solidify the membrane. The as-spun fibers were soaked in ethanol bath for 3 days to remove the residual solvent and non-solvent additives from the resultant membranes. At last, the wetting fibers were dried in air at room temperature until to receive hydrophobic porous membranes. The spinning conditions and detailed parameters were listed in Table 1.

\subsection{Membrane morphology study}

The morphology of membrane was investigated with a HITACHI S-3000N scanning electron microscope (SEM) (Hitachi Ltd., Japan). Membrane samples were frozen in liquid nitrogen, fractured to obtain fragments, and sputtered with platinum using a HITACHI E-1010 Ion Sputtering device for SEM observation.

\subsection{Porosity, pore size and pore size distribution}

The overall porosity was usually determined by gravimetric method, determining the weight of liquid contained in the mem-

Table 1

Process parameters and spinning conditions.

\begin{tabular}{ll}
\hline Process parameters/spinning conditions & Value \\
\hline & PVDF/DMAc/LiCl/PEG 1500 $(12 / 80 / 5 / 3)$ \\
& PVDF/DMAc/LiCl $(12 / 83 / 5)$ \\
Dope solution composition (wt\%) & PVDF/DMAc/PEG 1500 $(12 / 83 / 5)$ \\
& PVDF/DMAc $(12 / 88)$ \\
Mixing temperature $\left({ }^{\circ} \mathrm{C}\right)$ & 50 \\
Mixing time $(\mathrm{h})$ & 48 \\
Spinneret temperature $\left({ }^{\circ} \mathrm{C}\right)$ & Room temperature \\
Dope extrusion rate $(\mathrm{ml} / \mathrm{min})$ & 20 \\
Spinneret OD/ID $(\mathrm{mm} / \mathrm{mm})$ & $1.4 / 0.7$ \\
Bore liquid & Ultrapure water \\
Bore liquid flow rate $(\mathrm{ml} / \mathrm{min})$ & $10-20$ \\
External coagulant & Tap water \\
Air gap distance $(\mathrm{cm})$ & $8-10$ \\
Bore liquid temperature $\left({ }^{\circ} \mathrm{C}\right)$ & 20 \\
External coagulant temperature $\left({ }^{\circ} \mathrm{C}\right)$ & 20 \\
Take-up speed $(\mathrm{m} / \mathrm{s})$ & 0.35 \\
Room relative humidity $(\%)$ & $60-75$
\end{tabular}

a Outer diameter/inner diameter. 
brane pores. The porosity $\varepsilon$ of the PVDF hollow fiber was calculated by the following equations [2]:

$\varepsilon=\frac{\left(w_{1}-w_{2}\right) / D_{\mathrm{W}}}{\left(w_{1}-w_{2}\right) / D_{\mathrm{W}}+w_{2} / D_{\mathrm{P}}}$,

where $w_{1}$ is the weight of the wet membrane, $w_{2}$ is the weight of the dry membrane, $D_{\mathrm{W}}$ is the water density and $D_{\mathrm{P}}$ is the polymer density.

These parameters were determined from the dried membranes using the gas permeation method developed by Kong and Li [32]. A test module with the length of about $5 \mathrm{~cm}$ and containing 5 dried fibers was made and both ends of the hollow fibers were potted using epoxy resin. The upstream pressure was in the range from 0 to $0.5 \mathrm{MPa}$ at $10 \mathrm{KPa}$ pressure increment interval. Purified nitrogen was used as the test gas and the permeation flux was measured using a soap-bubble flow meter. The intercept $\left(K_{\mathrm{o}}\right)$ and slope $\left(P_{\mathrm{o}}\right)$ were determined by plotting the pressure-normalized permeate flux versus average pressure, and the average pore size $(r)$ was calculated from following equation [15]:

$r=\frac{16}{3}\left(\frac{P_{\mathrm{o}}}{K_{\mathrm{o}}}\right)\left(\frac{8 R T}{\pi M}\right)^{0.5} \times \mu$

where $R$ is the gas constant, $T$ is the absolute temperature, $M$ is the molecular weight and $\mu$ is the gas viscosity.

\subsection{Dynamic contact angle measurement}

The dynamic contact angle of the PVDF hollow fiber was measured by a tensiometer (DCAT11, DataPhysics Instruments Ltd., Germany). A sample fiber was held on the arm of an electrobalance, and then immersed $5 \mathrm{~mm}$ long into Milli-Q water and successively emerged out at an interfacial moving rate of $0.2 \mathrm{~mm} / \mathrm{min}$ to complete a cycle. In the loop, the weight difference was continuously recorded by the electrobalance and contact angle was calculated based on the Wilhemy method. Three immersion-emersion cycles were carried out for each specimen, and each run was repeated three times for all the hollow fiber samples.

\subsection{Desalination experiment}

Experiments of DCMD with sodium chloride solution were carried out to evaluate the permeate performance of prepared membranes. The schematic representation of DCMD set-up is shown in Fig. 2. The dry PVDF hollow fibers in the number of 50 pieces were assembled into a polyester tube (diameter $(\mathrm{mm})$ $d_{\text {in }} / d_{\text {out }}=15 / 20$ ) with two UPVC T-tubes and two ends of the bundle of fibers were sealed with solidified epoxy resin to form a membrane module. The total membrane length and the effective membrane length were 240 and $100 \mathrm{~mm}$, respectively. The hot salt solution as the feed liquid flowed through the lumen side of the fibers, whereas the cold water flowed through the shell side. Both solutions were circulated in the membrane module with the help of two magnetic pumps (MP-15RN, Shanghai Seisun Bumps, China). The circulation feed rate was $0.50 \mathrm{~m} / \mathrm{s}$, while the permeation side being $0.15 \mathrm{~m} / \mathrm{s}$, which were adjusted by two rotameters (LZS-15, Yuyao Yinhuan Flowmeter, China). The feed and the cold water flowed co-currently through the module. The feed temperature was controlled by a Pt-100 sensor and a heater connected to an external thermostat (XMTD-2202, Yongshang Instruments, China) and the temperature of cold distillate water was controlled by pumping through a spiral glass heat exchanger located in the constant temperature trough of the cooler (SDC-6, Nanjing Xinchen Biotechnology, China). The temperature of both fluids was monitored at the inlet and outlet of the membrane module using four Pt-100 thermoresistances connected to a digital meter (Digit RTD, model XMT-808, Yuyao Changjiang Temperature Meter Instruments, China) with an accuracy of $\pm 0.1^{\circ} \mathrm{C}$. The concentration of $\mathrm{NaCl}$ in the distillate cold water was investigated with an electric conductivity monitor (CM-230A, Shijiazhuang Create Instrumentation Technologies, China). The permeate flux of the membranes $J$ was calculated by the following equation:

$J=\frac{\Delta W}{A \Delta t}$,

where $J$ is the permeate flux $\left(\mathrm{kg} / \mathrm{m}^{2} \mathrm{~h}\right), \Delta W$ is the quantity of distillate $(\mathrm{kg}), A$ is the inner surface area of the hollow fiber membranes $\left(\mathrm{m}^{2}\right)$ and $\Delta t$ is the sampling time $(\mathrm{h})$.

The rejection coefficient $R$ of hollow fiber membranes was calculated according to the following equation:

$R=\frac{C_{f}-C_{p}}{C_{f}}$

where $C_{f}$ is the concentration of the feed and $C_{p}$ is the concentration of the permeated.

\section{Results and discussions}

\subsection{Effect of non-solvent additives on membranes morphology}

The hollow fiber membranes spun from PVDF/DMAc, PVDF/PEG 1500/DMAc, PVDF/LiCl/DMAc and PVDF/LiCl/PEG 1500/DMAc dope were numbered as M-1, M-2, M-3 and M-4, respectively. The morphologies of the hollow fibers are shown in Figs. 3-6. The larger and longer macrovoids from the inner wall can be observed in the fibers spun with $5 \mathrm{wt} \%$ PEG 1500 additives (Fig. 4, M-2a) in comparison with that without an additive (Fig. 3, M-1a). While as LiCl added into the system, the size of macrovoids decreased, the structure being stretched down like a finger from the underneath of membrane skin (Fig. 5, M-3a; Fig. 6, M-4a). The presence of PEG 1500 favored the formation of thinner fiber skins, which was confirmed

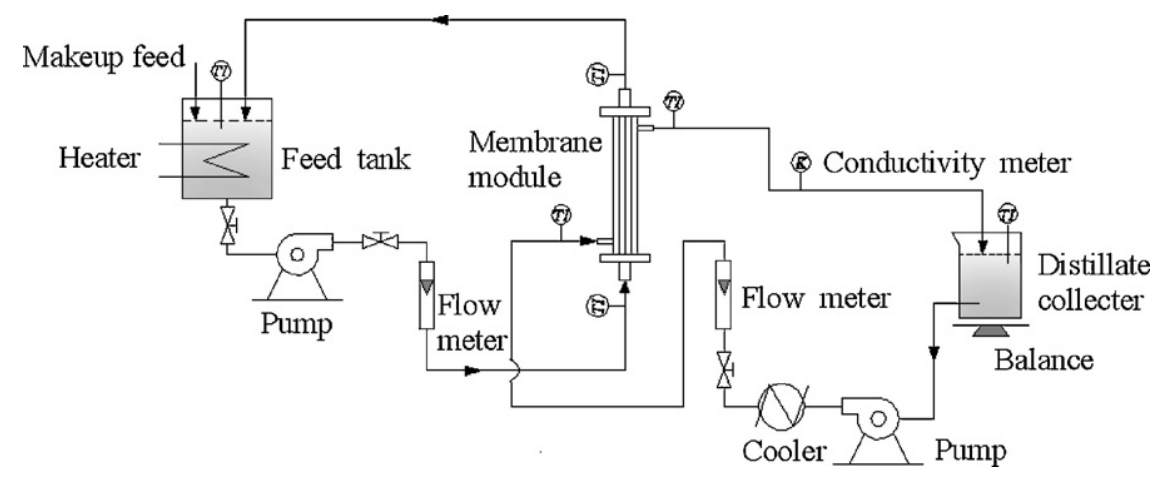

Fig. 2. Schematic diagram of the experimental DCMD set-up. 


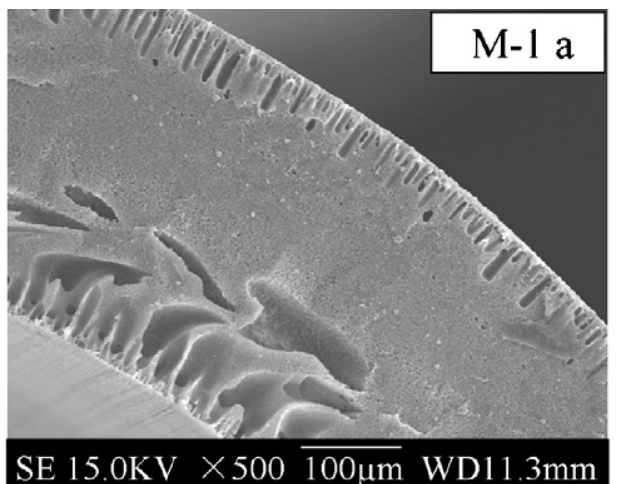

Cross section

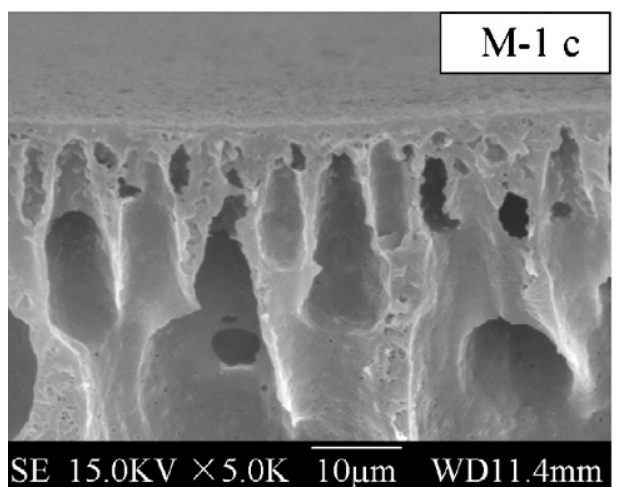

Cross section near inner layer

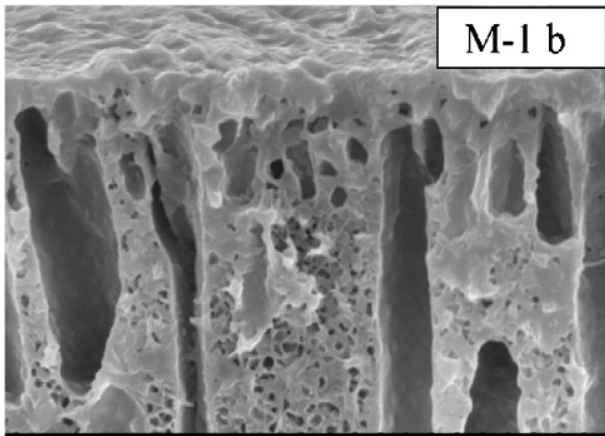

SE $15.0 \mathrm{KV} \times 5.0 \mathrm{~K} \overline{10 \mu \mathrm{m}} \mathrm{WD} 11.5 \mathrm{~mm}$

Cross section near outer layer

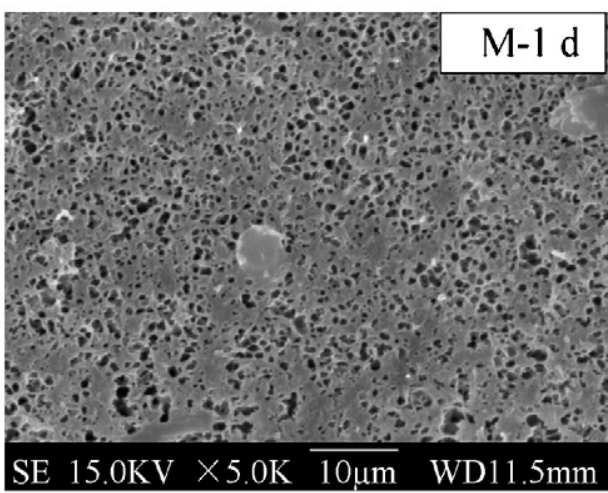

Middle structure

Fig. 3. SEM morphology of PVDF hollow fiber membrane from the PVDF/DMAc dope solution.

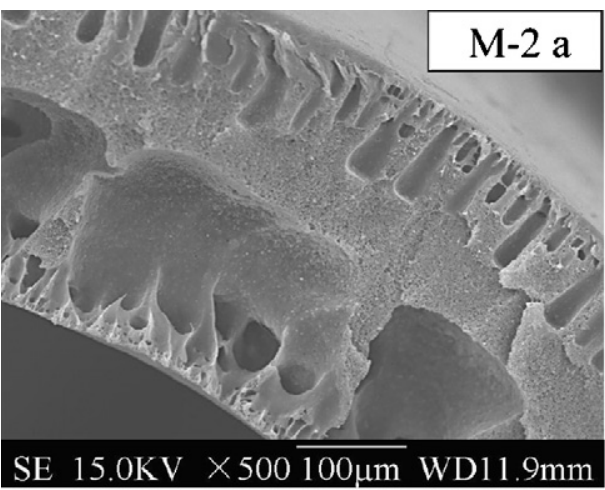

Cross section

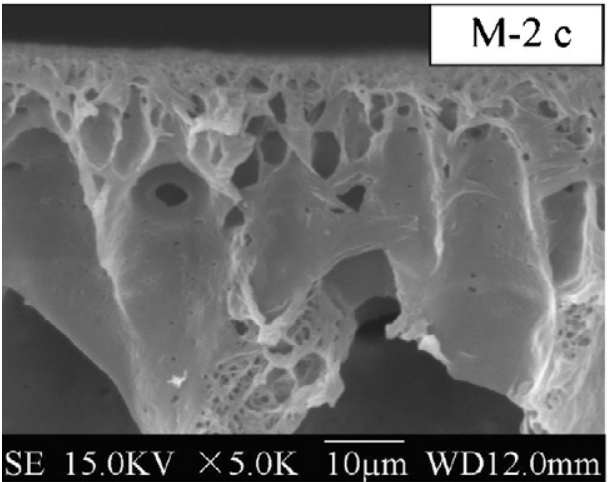

Cross section near inner layer

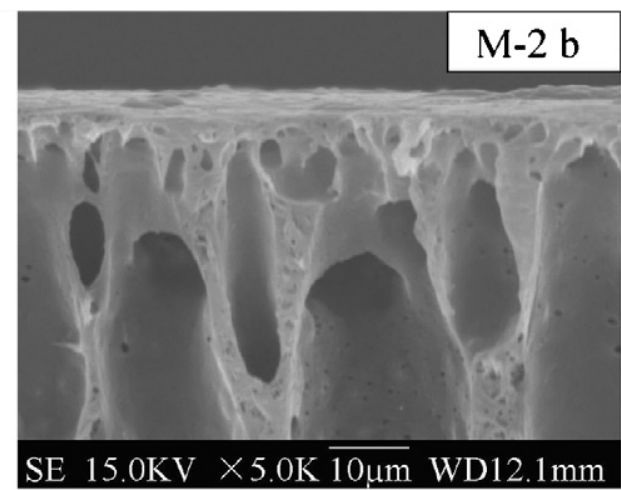

Cross section near outer layer

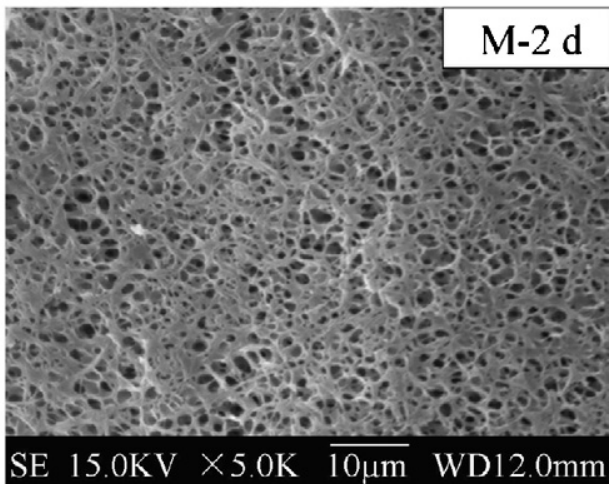

Middle structure

Fig. 4. SEM morphology of PVDF hollow fiber membrane from the PVDF/DMAc/PEG 1500 dope solution. 


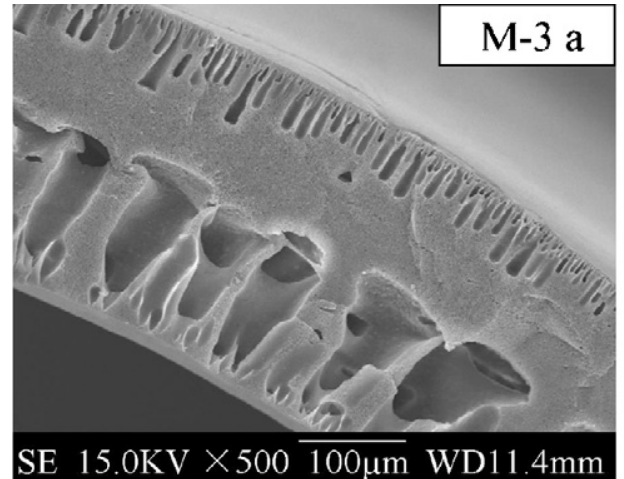

Cross section

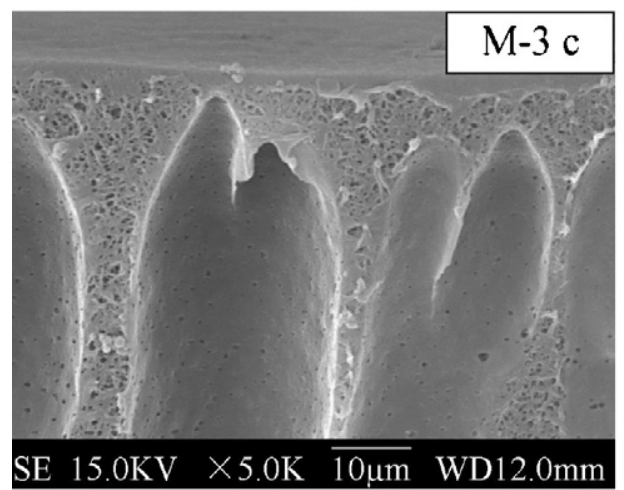

Cross section near inner layer

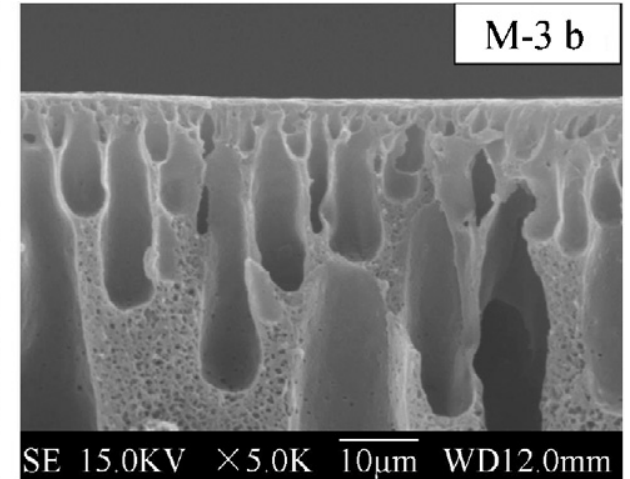

Cross section near outer layer

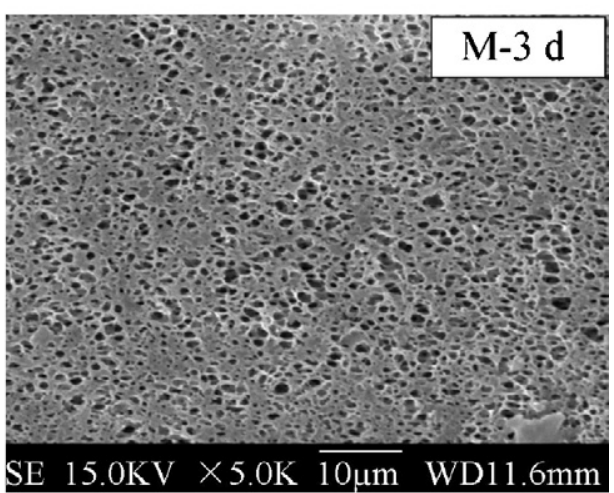

Middle structure

Fig. 5. SEM morphology of PVDF hollow fiber membrane from the PVDF/DMAc/LiCl dope solution.

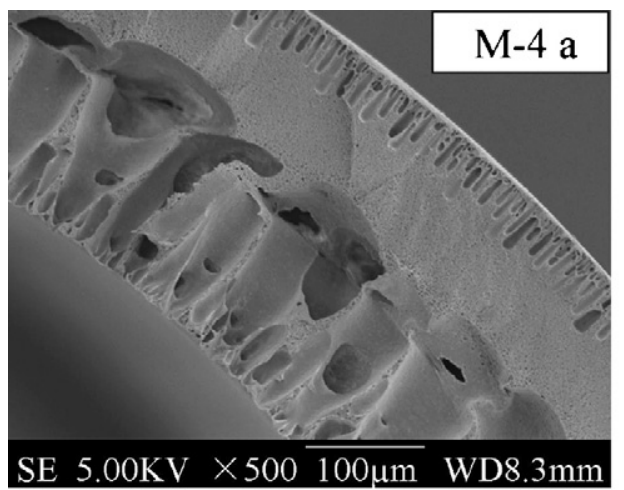

Cross section

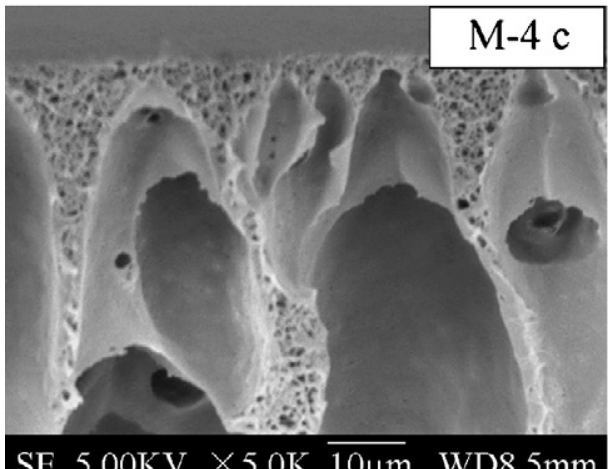

Cross section near inner layer

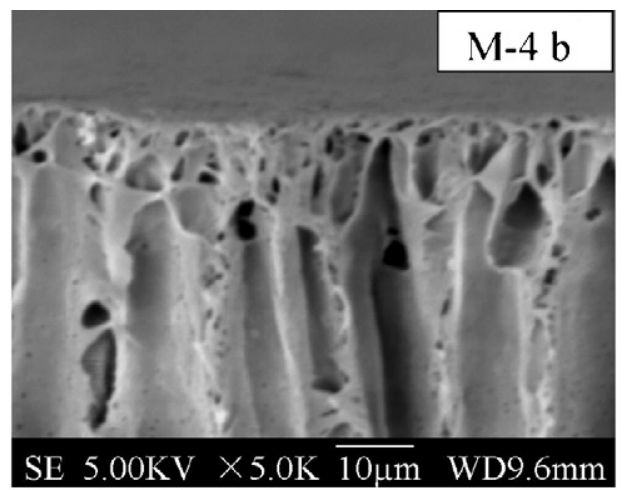

Cross section near outer layer

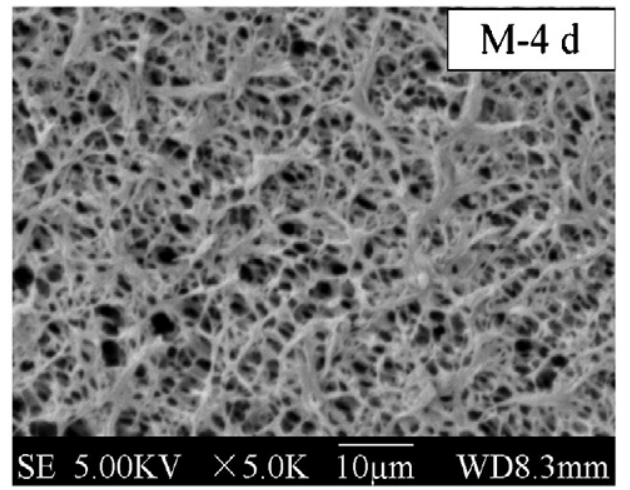

Middle structure

Fig. 6. SEM morphology of PVDF hollow fiber membrane from the PVDF/DMAc/LiCl/PEG 1500 dope solution. 
from the cross-section morphology near outer layer and inner layer of the M-2 membranes (Fig. 4, M-2b and M-2c) when compared with the membranes prepared with PEG 1500 as the additive and without it (Fig. 3, M-1b and M-1c; Fig. 5, M-3b and M-3c). Between the cavities beneath the outer and inner skin of the hollow fibers, the cross-section morphology of all the membranes was altered to the sponge-like structure. With the addition of $\mathrm{LiCl}$ in the dope, by comparing M-1d, M-2d with M-3d, it was found that the micropores in the middle structure increased apparently. Compared with other three membranes, the M-4 membranes have longer fingerlike cavities, ultra-thin skins and the porous network sponge-like structure, as shown in Fig. 6. This kind of microstructure may provide the PVDF hollow fibers with less resistance for water vapor transporting through the membranes and ensure the membranes with high permeate flux.

The above observations can be associated with the variation of the thermodynamic and kinetic properties of the dope system with different non-solvent additive. Compared with the system without an additive, PEG 1500 addition increased the dope's thermodynamic instability in reaction with water due to its non-solvent effect, which facilitated a rapid phase demixing and resulted in macrovoids and ultra-thin skin formation, thus the PEG 1500 acted as a phase separation enhancer. $\mathrm{LiCl}$ possessed strong interactions with the polymer and solvent, the addition of it can enhance the viscosity of the PVDF/DMAc dope solution significantly. The strong interactions among the components of the dope tended to delay the dope precipitation, so the macrovoids became smaller and developed to the finger-like structures, at the same time, the sponge-like structures changed to be more porous and the porosity of the membranes got improved. In the case of adding the mixture as additive, owing to the synergistic effect of $\mathrm{LiCl}$ and PEG 1500, macrovoids expanded to the finger-like structures, the skin got thinner and the as-spun membrane attained porous network sponge-like structure.

\subsection{Characterization of hollow fiber membranes}

The pore size distributions of the membranes are presented in Fig. 7. It can be seen that the pore size distribution of the membranes is in the following sequence: $\mathrm{M}-2>\mathrm{M}-1>\mathrm{M}-4>\mathrm{M}-3$ and the maximum diameter of the membrane pores is $0.90,0.50,0.50$, and $0.23 \mu \mathrm{m}$, respectively. From Fig. 7, it can also be found that the pores of M-3 and M-4 membranes show narrower distributions than M1 and M-2 membranes, which may minimize the water leakage through the membranes and keep high reject ratio for desalination.

Because of the addition of PEG 1500, the membrane surface became rough. As a result, the dynamic contact angle of the M-2 membranes increased to $118.50^{\circ}$ compared to $85.82^{\circ}$ of the M-1 membranes and $93.86^{\circ}$ of the M-3 membranes. The porosity of the M-4 hollow fibers was $79.7 \%$, whereas the porosity of the M-1, M2 and M-3 membranes were $68.7 \%, 72.4 \%$ and $77.5 \%$, respectively, which further verified that the mixture of $\mathrm{LiCl}$ and PEG 1500 as a non-solvent additive can enhance membrane porosity. The more detailed data of membranes characteristics was listed in Table 2.

\subsection{Permeability and solute rejection}

The fabricated fibers were tested for the DCMD process. During the experiment, the hot $3.5 \mathrm{wt} \%$ aqueous sodium chloride solution and the cold water, co-currently flow through the lumen and shell sides of hollow fibers, respectively. The inlet temperature of the hot salt solution, $T_{f}$, is adjusted from 30 to $80^{\circ} \mathrm{C}$ and the inlet temperature of the cold distillate, $T_{p}$, is kept at constant $20.0^{\circ} \mathrm{C}$. The water permeate flux based on the fibers inner surface area is shown in Fig. 8. It can be observed that the M-4 membrane with higher flux compared with other three hollow fibers. The permeate flux is significantly influenced by membrane morphology. Although all
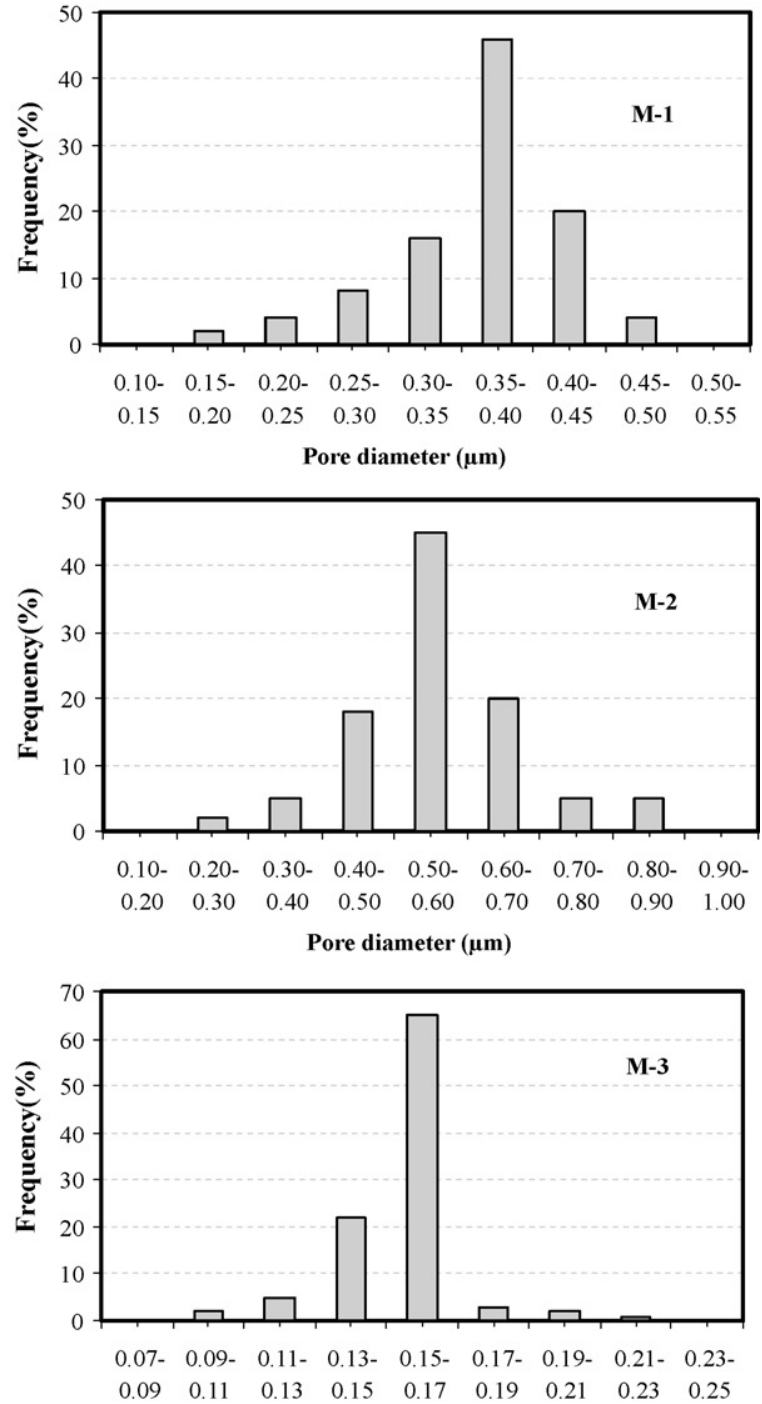

Pore diameter $(\mu \mathrm{m})$

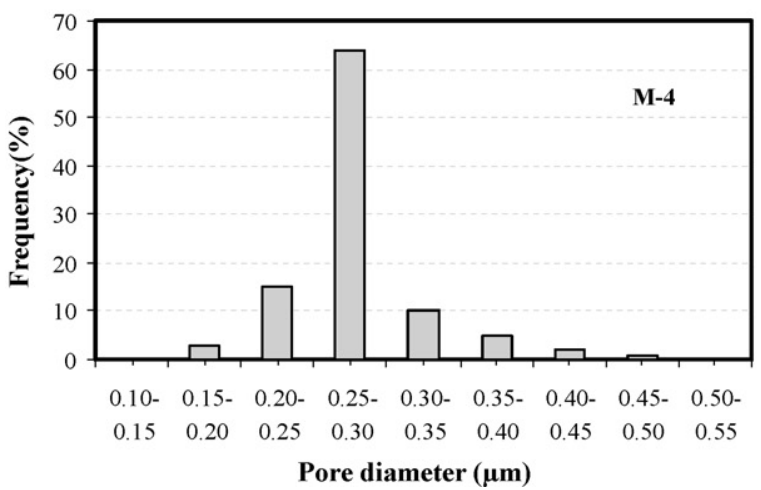

Fig. 7. Pore size distribution of the PVDF membranes spun from different dope solutions.

the four membranes have macrovoids or finger-like cavities underneath both the outer and inner surfaces, the M- 4 membrane has a special sponge-like structure between the finger-like cavities, which is more porous. Besides, the skins of M-4 membrane are thinner than those of other membranes. All of these can reduce the resistance of mass transfer, so the higher permeate flux was obtained. During the desalination process, although the temperature difference at the outlet of the membrane module is $41.6^{\circ} \mathrm{C}$ as 
Table 2

Measured data of membranes characteristics.

\begin{tabular}{|c|c|c|c|c|c|}
\hline Membrane code & Dynamic contact angle $\left({ }^{\circ}\right)$ & Porosity (\%) & $\mathrm{OD}(\mathrm{mm})$ & ID (mm) & Wall thickness (mm) \\
\hline M-1 & 85.82 & 68.7 & 0.98 & 0.72 & 0.13 \\
\hline M-2 & 118.50 & 72.4 & 1.20 & 0.94 & 0.13 \\
\hline$M-3$ & 93.86 & 77.5 & 1.20 & 0.94 & 0.13 \\
\hline M-4 & 105.21 & 79.7 & 1.20 & 0.94 & 0.13 \\
\hline
\end{tabular}

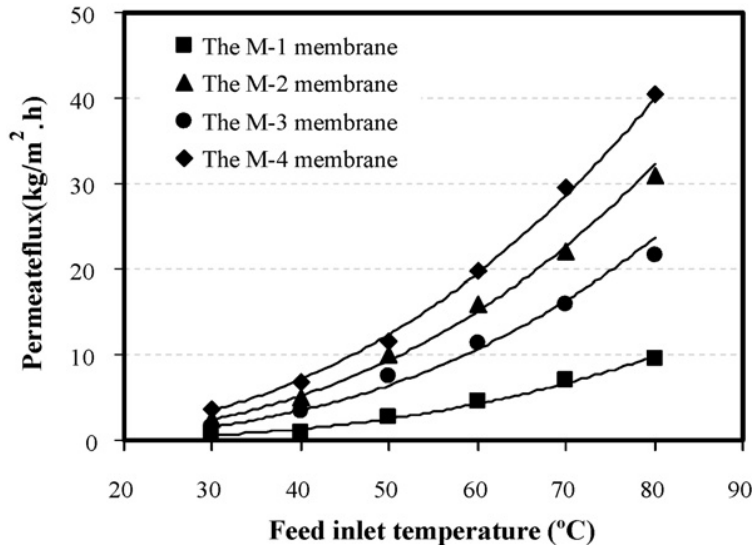

Fig. 8. Permeate flux as a function of feed temperature.

compared to $61.8^{\circ} \mathrm{C}$ at the inlet of the membrane module, the transmembrane water permeate flux can achieve $40.5 \mathrm{~kg} / \mathrm{m}^{2} \mathrm{~h}$ when the inlet temperature of hot solution is $81.8^{\circ} \mathrm{C}$ as listed in Table 3 .

Compared with the permeate flux of $42.7 \mathrm{~kg} / \mathrm{m}^{2} \mathrm{~h}$ reported by Wang et al. [1], the permeate flux declined to $31.0 \mathrm{~kg} / \mathrm{m}^{2} \mathrm{~h}$ for the M-2 membrane with the hot feed temperature at $80.0^{\circ} \mathrm{C}$ when both membranes were prepared with only one soluble organic non-solvent additive. This difference can be mainly attributed to the different bore fluid composition. The bore fluid $\mathrm{NMP} / \mathrm{H}_{2} \mathrm{O}$ (80/20 wt\%) in [1] made the gelation rate become very slow near the lumen of hollow fiber and the finger-like cavities almost extend from the underneath of membrane outer surface to the inner surface, which effectively reduced the resistance of mass transfer and enhanced permeate flux. In addition, the lower gelation rate induced the increase of surface porosity, which was also helpful to the improvement of permeate flux.

However, there was great difference of the $\mathrm{NaCl}$ rejection among the spun membranes. The $\mathrm{NaCl}$ rejection of the $\mathrm{M}-1$ and $\mathrm{M}-3$ membranes achieved $100 \%$ and the conductivity of the distillate water kept constant during the test process of permeability and solute rejection. The conductivity of the distillate water from the M-4 membrane was less than $15 \mu \mathrm{S} / \mathrm{cm}$, indicating that the rejection achieved $99.99 \%$. Due to the high permeate flux and solute rejection, the M-4 membrane may be of great potential to be utilized in the MD process. It must be noted that the M-2 membrane achieved

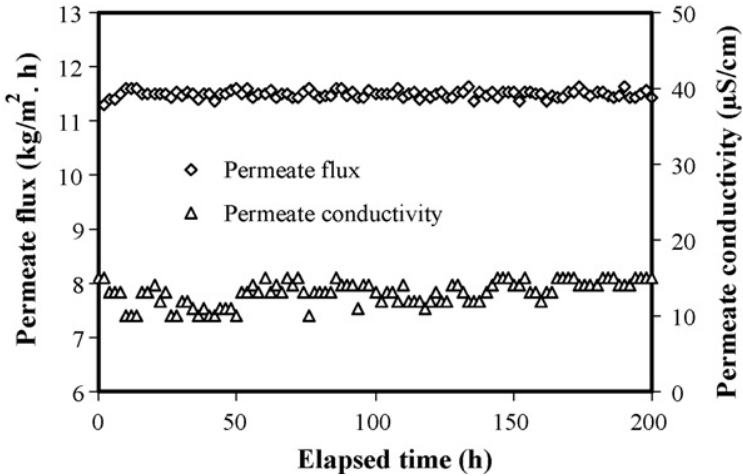

Fig. 9. Variation of permeate flux and conductivity as a function of elapsed time during the desalination experiment.

the lowest $\mathrm{NaCl}$ rejection, the conductivity of the distillate water increased to $84 \mu \mathrm{S} / \mathrm{cm}$ from the initial conductivity of $2 \mu \mathrm{S} / \mathrm{cm}$, which indicated that the M-2 membrane was not fit for membrane distillation.

\subsection{Performance stability}

To achieve a high-performance hydrophobic membrane, it is important to sustain the permeability and solute rejection during the practical application. To investigate the retaining performance stability of the M-4 membrane, a 200 h continuously desalination experiment of aqueous sodium chloride solution was conducted with the feed solution at constant $50^{\circ} \mathrm{C}$ and the cold distillate water at $20.0^{\circ} \mathrm{C}$. The feed $\mathrm{NaCl}$ concentration was kept at $3.5 \mathrm{wt} \%$. The other operating parameters of the DCMD process were in accordance with the permeability tests. The result of desalination performance is shown in Fig. 9. It can be seen that the permeate flux maintains about $11.5 \mathrm{~kg} / \mathrm{m}^{2} \mathrm{~h}$ during experiment and there are no obvious changes of permeate flux. The permeate conductivity stabilized at about $10.0-15.0 \mu \mathrm{S} / \mathrm{cm}$. All of these demonstrated that the M-4 membrane had a stable permeability and solute rejection and it was suitable for MD applications.

\subsection{Comparison with other MD membranes}

Table 4 lists a performance comparison between the current work and the previous investigations. It can be observed that the

Table 3

DCMD operating conditions and permeate flux of the M-4 hollow fibers.

\begin{tabular}{|c|c|c|c|c|c|c|}
\hline$T_{\text {f-inlet }}\left({ }^{\circ} \mathrm{C}\right)$ & 30.5 & 40.2 & 50.0 & 61.4 & 71.3 & 81.8 \\
\hline$T_{p \text {-inlet }}\left({ }^{\circ} \mathrm{C}\right)$ & 20.0 & 20.0 & 20.0 & 20.0 & 20.0 & 20.0 \\
\hline$\Delta T_{\text {inlet }}\left({ }^{\circ} \mathrm{C}\right)$ & 10.5 & 20.2 & 30.0 & 41.4 & 51.3 & 61.8 \\
\hline$T_{\text {f-outlet }}\left({ }^{\circ} \mathrm{C}\right)$ & 29.0 & 37.5 & 46.3 & 55.5 & 65.8 & 75.5 \\
\hline$T_{p \text {-outlet }}\left({ }^{\circ} \mathrm{C}\right)$ & 21.5 & 22.8 & 25.0 & 27.7 & 32.3 & 33.9 \\
\hline$\Delta T_{\text {outlet }}\left({ }^{\circ} \mathrm{C}\right)$ & 7.5 & 14.7 & 21.3 & 27.8 & 33.5 & 41.6 \\
\hline Feed flow rate $(\mathrm{m} / \mathrm{s})$ & 0.50 & & & & & \\
\hline Permeate flow rate $(\mathrm{m} / \mathrm{s})$ & 0.15 & & & & & \\
\hline Effective membrane area $\left(\mathrm{cm}^{2}\right)$ & 147 & & & & & \\
\hline Effective membrane length (cm) & 10 & & & & & \\
\hline Packing fraction of membranes (\%) & 32 & & & & & \\
\hline Permeate flux $\left(\mathrm{kg} / \mathrm{m}^{2} \mathrm{~h}\right)$ & 3.7 & 6.8 & 11.5 & 19.8 & 29.6 & 40.5 \\
\hline
\end{tabular}


Table 4

Comparison of the maximum flux obtained in this study with the literature for DCMD processes.

\begin{tabular}{|c|c|c|c|c|c|c|c|c|}
\hline \multirow[t]{2}{*}{ Membrane } & \multirow[t]{2}{*}{ Reference } & \multirow{2}{*}{$\begin{array}{l}\text { Permeate flux } \\
\left(\mathrm{kg} / \mathrm{m}^{2} \mathrm{~h}\right)\end{array}$} & \multicolumn{3}{|l|}{ Feed solution } & \multicolumn{2}{|l|}{ Permeate solution } & \multirow[t]{2}{*}{ Configuration } \\
\hline & & & $\mathrm{NaCl}$ concentration & $\begin{array}{l}\text { Inlet temperature } \\
\left({ }^{\circ} \mathrm{C}\right)\end{array}$ & $\begin{array}{l}\text { Flow rate } \\
(\mathrm{m} / \mathrm{s})\end{array}$ & $\begin{array}{l}\text { Inlet temperature } \\
\left({ }^{\circ} \mathrm{C}\right)\end{array}$ & $\begin{array}{l}\text { Flow rate } \\
(\mathrm{m} / \mathrm{s})\end{array}$ & \\
\hline PP hollow fiber & [33] & 28 & $1.0 w t \%$ & 80 & 0.11 & 20.0 & 0.03 & Concurrent \\
\hline PP hollow fiber & {$[34]^{\mathrm{a}}$} & 13.5 & $3.5 \mathrm{wt} \%$ & 85 & 0.37 & 20.0 & - & Concurrent \\
\hline PP hollow fiber & {$[35]$} & 38.8 & $3.0 w t \%$ & 90 & 0.04 & 17.0 & 0.49 & Cross-flow \\
\hline PVDF flat sheet membrane & {$[38]$} & 32.4 & Distilled water & 70 & 2.59 & 20.0 & 4.67 & Cross-flow \\
\hline PVDF hollow fiber & [1] & 42.7 & $3.5 \mathrm{wt} \%$ & 79.3 & 1.60 & 17.5 & 0.80 & Concurrent \\
\hline PVDF hollow fiber & This study & 40.5 & $3.5 \mathrm{wt} \%$ & 81.8 & 0.50 & 20.0 & 0.15 & Concurrent \\
\hline
\end{tabular}

a The permeate flow rate in $\mathrm{m} / \mathrm{s}$ was not provided in ref [34].

obtained data in this study is comparable or even better than the most of the previous reports and there is only one data reported by Wang and Chuang which is higher than the data obtained in this study. But it must be noted that the flow rates of feed and permeate in [1] were 1.60 and $0.80 \mathrm{~m} / \mathrm{s}$, respectively, which were much higher than the corresponding flow rates in this study. It was well known that the permeate flux increased by increasing flow rate because the high flow rate can diminish the polarization effect [36]. Besides, the packing fraction of membranes in the module in [1] was $48 \%$ and it was $32 \%$ in this study. The high packing fraction could mitigate the channelling effect and enhance the permeate flux [37]. The high flux obtained in this study can be mainly attributed to the synergistic effect of LiCl and PEG 1500, which optimized membrane characteristics such as thickness of the skin, porosity, pore size, pore size distribution, and dynamic contact angle. It is believed that if the membrane fabrication optimizations which were attempted in this work are accompanied with higher flow rate and more efficient module designs to improve the flow pattern and diminish the temperature polarization effect, even higher flux is achievable in the MD process.

\section{Conclusions}

In the present work, the mixture of $\mathrm{LiCl}$ and PEG 1500 as non-solvent was introduced to fabricate hydrophobic PVDF hollow fiber membrane by phase inversion process. Compared with other three PVDF membranes, the membranes spun from PVDF/LiCl/PEG 1500/DMAc dope had longer finger-like cavities, ultra-thin skins and porous network sponge-like structure owing to the synergistic effect of $\mathrm{LiCl}$ and PEG 1500. In addition, the membrane also exhibited high porosity and good hydrophobicity.

This as-spun membrane was successfully applied in MD process. During the desalination process of $3.5 \mathrm{wt} \%$ sodium chloride solution, the maximum transmembrane permeate flux achieved $40.5 \mathrm{~kg} / \mathrm{m}^{2} \mathrm{~h}$ with $99.99 \% \mathrm{NaCl}$ rejection. To investigate the retaining performance stability of the membrane, a $200 \mathrm{~h}$ continuously desalination experiment was conducted. The desalination performance showed that the PVDF membrane had stable permeate flux and solute rejection, the permeate conductivity could drop to $15 \mu \mathrm{S} / \mathrm{cm}$. All of these demonstrated that the M-4 membrane had a stable permeability and solute rejection and it was suitable for MD applications.

\section{Acknowledgments}

Financial support provided by the National Natural Science Foundation of China (Grant no. 50678169), the National Science and Technology Support Program of China (Grant no. 2006BAJ08B05) and Research Foundation of The Chinese Academy of Sciences for Youth Scholars (the project of preparation and optimization of hydrophobic hollow fibers and membrane modules) are gratefully acknowledged.

\section{References}

[1] K.Y. Wang, T.S. Chung, M. Gryta, Hydrophobic PVDF hollow fiber membranes with narrow pore size distribution and ultra-thin skin for the fresh water production through membrane distillation, Chem. Eng. Sci. 63 (2008) 2587-2589.

[2] C.S. Feng, B.L. Shi, G.M. Li, et al, Preparation and properties of microporous membrane from poly(vinylidene fluoride-co-tetrafluoroethylene) (F2.4) for membrane distillation, J. Membr. Sci. 237 (2004) 15-24.

[3] K.W. Lawson, D.R. Lloyd, Membrane distillation, J. Membr. Sci. 124 (1997) 1-25.

[4] J.H. Hanemaaijer, J.v. Medevoort, A.E. Jansen, et al., Memstill membrane distillation-a future desalination technology, Desalination 199 (2006) 175-176.

[5] E. El-Zanati, K.M. El-Khatib, Integrated membrane-based desalination system, Desalination 205 (2007) 15-25.

[6] M. Safavi, T. Mohammadi, High-salinity water desalination using VMD, Chem. Eng. J. 149 (2009) 191-195.

[7] M. Khayet, P. Godino, J.I. Mengual, Theory and experiments on sweeping gas membrane distillation, J. Membr. Sci. 165 (2000) 261-272.

[8] T.Y. Cath, V.D. Adams, A.E. Childress, Experimental study of desalination using direct contact membrane distillation: a new approach to flux enhancement, J. Membr. Sci. 228 (2004) 5-16

[9] C.M. Guijt, G.W. Meindersma, T. Reith, A.B. de Haan, Air gap membrane distillation: 2 . Model validation and hollow fibre module performance analysis, Sep. Purif. Technol. 43 (2005) 245-255.

[10] M.S. El-Bourawi, Z. Ding, R. Ma, M. Khayet, A framework for better understanding membrane distillation separation process, J. Membr. Sci. 285 (2006) 4-29.

[11] M. Gryta, Influence of polypropylene membrane surface porosity on the performance of membrane distillation process, J. Membr. Sci. 287 (2007) 6768.

[12] M. Khayet, A. Velazquez, J.I. Mengual, Modelling mass transfer through a porous partition: effect of pore size distribution, J. Non-Equilib. Thermodyn. 29 (2004) 279-299.

[13] M. Khayet, T. Matsuura, Pervaporation and vacuum membrane distillation processes: modeling and experiments, AIChE J. 50 (2004) 1697-1712.

[14] J. Phattaranawik, R. Jiraratananon, A.G. Fane, Effect of pore size distribution and air flux on mass transport in direct contact membrane distillation, J. Membr. Sci. 215 (2003) 75-85.

[15] D.L. Wang, K. Li, W.K. Teo, Porous PVDF asymmetric hollow fiber membranes prepared with the use of small molecular additives, J. Membr. Sci. 178 (2000) 13-23.

[16] M. Khayet, C.Y. Feng, K.C. Khulbe, et al., Preparation and characterization of polyvinylidene fluoride hollow fiber membranes for ultrafiltration, Polymer 43 (2002) 3879-3890.

[17] D.J. Lin, H.H. Chang, T.C. Chen, Microporous PVDF membrane formation by immersion precipitation from water/TEP/PVDF system, Eur. Polym. J. 145(2002) 25-29.

[18] E. Fontananova, J.C. Jansen, A.C. Fontananova, et al., Effect of additives in the casting solution on the formation of PVDF membranes, Desalination 192 (2006) 190-197.

[19] W.H. Seol, Y.M. Lee, J.K. Park, Enhancement of the mechanical properties of PVDF membranes by non-solvent aided morphology control, J. Power Sources 170 (2007) 191-195.

[20] M.G. Buonomenna, P. Macchi, M. Davoli, et al., Poly(vinylidene fluoride) membranes by phase inversion: the role the casting and coagulation conditions play in their morphology, crystalline structure and properties, Eur. Polym. J. 43 (2007) 1557-1572.

[21] N. Singh, S.M. Husson, B. Zdyrko, et al., Surface modification of microporous PVDF membranes by ATRP, J. Membr. Sci. 262 (2005) 81-90.

[22] C.S. Feng, R. Wang, G.M. Li, et al., Factors affecting pore structure and performance of poly(vinylidene fluoride-co-hexafluoro propylene) asymmetric porous membrane, J. Membr. Sci. 277 (2006) 55-64.

[23] L.S. Wu, J.F. Sun, Q.R. Wang, Poly(vinylidene fluoride)/polyethersulfone blend membranes: effects of solvent sort, polyethersulfone and polyvinylpyrrolidone concentration on their properties and morphology, J. Membr. Sci. 285 (2006) 290-298.

[24] Y.H. Zhao, Y.L. Qian, B.K. Zhu, et al., Modification of porous poly(vinylidene fluoride) membrane using amphiphilic polymers with different structures in phase inversion process, J. Membr. Sci. 310 (2008) 567-576. 
[25] Y. Zhou, D.L. Xi, Porous PVDF/TPU blends asymmetric hollow fiber membranes prepared with the use of hydrophilic additive PVP (K30), Desalination 223 (2008) 438-447.

[26] M. Tomaszewska, Preparation and properties of flat-sheet membranes from poly(vinylidene fluoride) for membrane distillation, Desalination 104 (1996) $1-11$.

[27] E. Curcio, E. Fontananova, G. Di Profio, et al., Influence of the structural properties of poly(vinylidene fluoride)membranes on the heterogeneous nucleation rate of protein crystals, J. Phys. Chem. B 110 (2006)12438-12445.

[28] J.H. Kim, K.H. Lee, Effect of PEG additive on membrane formation by phase inversion, J. Membr. Sci. 138 (1998) 153-163.

[29] I.C. Kim, K.H. Lee, Effect of poly(ethylene glycol) 200 on the formation of a polyetherimide asymmetric membrane and its performance in aqueous solvent mixture permeation, J. Membr. Sci. 230 (2004) 183-188.

[30] J.J. Shieh, T.S. Chung, R. Wang, et al., Gas separation performance of poly(4vinylpyridine)/polyetherimide composite hollow fibers, J. Membr. Sci. 182 (2001) 111-123.

[31] K.Y. Wang, T. Matsuura, T.S. Chung, et al., The effects of flow angle and shear rate within the spinneret on the separation performance of poly(ethersulfone) (PES) ultrafiltration hollow fiber membranes, J. Membr. Sci. 240 (2004) 67-79.
[32] J.F. Kong, K. Li, An improved gas permeation method for characterising and predicting the performance of microporous asymmetric hollow fibre membranes used in gas absorption, J. Membr. Sci. 182 (2001) 272-281.

[33] M. Gryta, M. Tomaszewska, Heat transport in the membrane distillation process, J. Membr. Sci. 144 (1998) 211-222.

[34] M. Gryta, M. Tomaszewska, J. Grzechulska, et al., Membrane distillation of $\mathrm{NaCl}$ solution containing natural organic matter, J. Membr. Sci. 181 (2001) 279-287.

[35] L. Song, B. Li, K.K. Sirkar, et al., Direct contact membrane distillation-based desalination: novel membranes, devices, larger-scale studies, and a model, Ind. Eng. Chem. Res. 46 (2007) 2307-2323.

[36] Z.W. Ding, X.D. Chen, R.Y. Ma, Study on the channelling effect in hollow fiber module applied in membrane distillation by numerical simulation, Comput. Appl. Chem. 18 (2001) 499-504.

[37] M.A. Izquierdo-Gila, C. Ferńandez-Pineda, M.G. Lorenz, Flow rate influence on direct contact membrane distillation experiments: different empirical correlations for Nusselt number, J. Membr. Sci. 321 (2003) 356-363.

[38] J. Phattaranawik, R. Jiraratananon, A.G. Fane, Heat transport and membrane distillation coefficients in direct contact membrane distillation, J. Membr. Sci. 212 (2003) 177-193. 